Revista de Estudios Histórico-Jurídicos [Sección Historia del Derecho de América] XXXII (Valparaíso, Chile, 2010) [pp. 395 - 418]

\title{
LA INSTITUCIÓN DE LA JUSTICIA DE PAZ: LA RESOLUCIÓN DE CONTROVERSIAS VECINALES DE MENOR CUANTÍA EN MATERia CIVIL y COMERCial (SAN Rafael, MENDOZA, 1900-1916)
}

[The Institution of Justice of the Peace: Dispute Resolution Regarding Small Neighbouring Claims in Civil and Commercial Matters (San Rafael, Mendoza, 1900-1916)]

\author{
InÉs SANJURJo DE Driollet* \\ Universidad Nacional de Cuyo
}

Consejo Nacional de Investigaciones Científicas y Técnicas, Argentina

\section{RESUMEN}

El trabajo analiza la institución de la justicia de paz en una localidad del sur de Mendoza (Argentina). Se comienza por el estudio de la legislación hasta 1916, particularmente de las constituciones provinciales de 1900 y 1910, las respectivas leyes orgánicas y su articulación con los Códigos de Procedimiento dictados en la provincia al terminar el siglo XIX. Luego se dedica a las prácticas institucionales, con especial atención a las causas en materia civil y comercial entre 1900 y 1916, con el fin de ahondar en las connotaciones de la cultura jurídica local.

Palabras clave: Justicia de paz.

\section{ABSTRACT}

This article analyses the institution of the justice of the peace in a town located south of Mendoza (Argentina). We will begin by studying the legislation until 1916, especially of the provincial constitutions of 1900 and 1910, the respective organic laws and their articulation with the Codes of Procedure enacted in the province at the end of the $19^{\text {th }}$ Century. We will then study institutional practices, especially focused on civil and commercial matters between 1900 and 1916, in order to deepen into the local legal culture connotations.

KEYWORDS: Justice of the peace.

* Profesora de Historia Institucional Argentina de la Facultad de Ciencias Políticas y Sociales de la Universidad Nacional de Cuyo. Dirección postal: Juan José Paso 718,(5519) Cnel. Dorrego, Guaymallén, Provincia de Mendoza, Argentina. Correo electrónico: isanjurjo@mendoza-conicet.gov.ar 


\section{INTRODUCCIÓN}

En trabajos anteriores nos hemos referido a la organización de la justicia de menor cuantía en la provincia de Mendoza en el siglo XIX, particularmente hasta $1880^{1}$. También nos hemos dedicado al estudio de la configuración legal de la justicia de paz hacia el año 1900 y hemos realizado un acercamiento a las prácticas en torno a esta institución en el tránsito del siglo XIX al XX, a través del análisis de un conjunto de expedientes correspondientes al sureño departamento de San Rafael, en los que se ventilaron causas civiles (laborales, de familia, etc.), comerciales y penales ${ }^{2}$. Una aproximación cuantitativa dio como resultado estimativo -debido al escaso número de fuentes de que dispusimos-, que esta magistratura menor, distante de los tribunales superiores de la provincia, constituyó un espacio de resolución de los conflictos cotidianos en esa sociedad rural caracterizada por su rápido crecimiento al ritmo de la colonización agrícola, producida luego de la desaparición de la frontera indígena ${ }^{3}$.

En el presente artículo extenderemos el análisis de la legislación hasta la sancionada bajo la Constitución provincial de 1910, deteniéndonos particularmente en los Códigos de procedimientos que salieron a la luz en la provincia al finalizar el siglo XIX. Trataremos de observar la incidencia que esta normativa pudo tener en el ejercicio de esa justicia sui generis, administrada desde sus orígenes por jueces legos a los que la doctrina estipuló fallar según su conciencia y buscando previamente la conciliación entre las partes, casi paternalmente.

Luego ahondaremos en las prácticas institucionales durante la vigencia de las constituciones provinciales de 1900 y 1910, mediante un examen más detenido de los expedientes de la justicia de paz, limitándonos a los juicios radicados en el juzgado de la Villa 25 de Mayo en materia de derecho civil y comercial. Más particularmente atenderemos a contratos y transacciones en general, condición de los bienes y responsabilidad por daños, ciertamente en cuestiones de montos menores por corresponder a un juzgado de paz. Si bien no contamos con un corpus que pueda considerarse representativo desde la perspectiva cuantitativa, podremos, en cambio, escudriñar, entre las características de la cultura jurídica

${ }^{1}$ Sanjurjo, Inés, La justicia de paz en Mendoza. Leyes de 1872, 1876 y 1880, en Confluencia, 2 (Mendoza, primavera 2003, Facultad de Ciencias Políticas y Sociales, UNCuyo).

${ }^{2} \mathrm{Mi}$ agradecimiento al Dr. Luis María Caterina por las valiosas sugerencias realizadas a este trabajo, y al Sr. Pedro Félix González, empleado de la Circunscripción Judicial de San Rafael, quien desinteresadamente ayudó a encontrar los expedientes de la justicia de paz del período señalado.

${ }^{3}$ Sanjurjo, Inés Elena, Justicia de paz y cultura juridica en el largo siglo XIX en Mendoza (Argentina). El caso del departamento de San Rafael en el sur provincial: trabajo presentado en las III Jornadas de Trabajo y Discusión sobre el siglo XIX (c/subsidio CONICET), Grupo "Problemas y Debates del Siglo XIX" (G.XIX). CEHis., Departamento de Historia, Facultad de Humanidades, Universidad Nacional de Mar del Plata, 2009. A partir del 23 de marzo de 2010 publicado en un dossier dirigido por Darío Barriera en Nuevos Mundos Mundos Nuevos, Debates (2010) [en línea desde el 23 marzo 2010. URL : http://nuevomundo.revues.org/59257. Consultado el 20 abril 2010]. 
local ${ }^{4}$, cómo se vincularon las personas con la institución, y qué posibilidades de resolución de los conflictos cotidianos brindaba este espación.

El estudio a la vez nos permitirá vislumbrar el nivel de penetración que tuvo el Estado en esa sociedad periférica de reciente colonización. Esto resulta de interés dado que investigaciones anteriores han demostrado que en la época de la frontera con el indígena, el departamento de San Rafael exhibía un escaso grado de "estatalización" ${ }^{\text {. }}$ Esto se debía a la situación de marginalidad producida por la distancia a que se hallaba desde el centro político provincial y a la condición de frontera, que hacía del Comandante de las fuerzas de línea allí acantonadas una figura de tal magnitud que afectaba el desempeño de las funciones que las leyes asignaban a la autoridad civil nombrada por el gobierno provincial, incluso en lo relativo a la administración de justicia. Una vez suprimida la frontera $-y$ con ello la centralidad de la institución militar-, e incorporado plenamente ese territorio a la jurisdicción de la provincia y a su vida política y económica, pudo observarse un mayor grado de institucionalidad por el funcionamiento de la municipalidad creada en 1883 , no obstante el menoscabo que significaban las prácticas fraudulentas de la época en materia electoral, y las imposiciones de los agentes del gobierno. Además, se ha constatado la activa participación vecinal en las nuevas colonias agrícolas allí fundadas, en gran parte con población de base inmigratoria ${ }^{7}$. Ante esto, surge el interrogante sobre si el funcionamiento de la

4 "La noción de cultura jurídica se ha desarrollado como herramienta conceptual para la comprensión del derecho como fenómeno social, esto es, como proceso actualmente operante al interior de la sociedad. Si se intenta abarcar el derecho desde ese punto de vista, la mera referencia a los productos normativos (las leyes, las decisiones judiciales, los contratos, etc.) y a las instituciones jurídicas, su organización y sus procedimientos, es insuficiente; deja fuera todo un ámbito que pertenece a la significación social del derecho, a su funcionamiento en la sociedad. La descripción del funcionamiento social del derecho debe dar cuenta también de las actitudes, valoraciones y creencias que en relación al derecho son compartidas en una sociedad, pues ellas determinan la forma en que las personas se relacionan, como operadores o como público, con las instituciones y las normas jurídicas": Accatino SCAGLIOTTI, Daniela, El saber dogmático en nuestra cultura jurídica, en Revista de Derecho, 8 (Valdivia, Universidad Austral de Chile, diciembre 1997), pp. 7-18.

${ }^{5}$ La cuestión del conocimiento de la cultura jurídica de una sociedad local a través de los expedientes de los juzgados de paz es tratada desde la perspectiva teórico metodológica por PAlacio, Juan Manuel, Hurgando en las bambalinas de "la paz del trigo": Algunos problemas teórico-metodológicos que plantea la historia judicia”, en Quinto Sol, 9-10 (La Pampa, 20052006, versión electrónica), pp. 99 ss.

${ }^{6}$ El término es usado en el sentido, precisamente, de la identificación del orden social con el orden estatal liberal, tal como lo hace Hespanha, Antonio, Cultura juridica europea. Sintesis de un milenio (Madrid, Tecnos, 2002), p. 173.

${ }^{7}$ Los censos nacionales muestran que el crecimiento poblacional del sur mendocino fue muy significativo si lo comparamos con las cifras provinciales. Entre 1895 y 1914 el total de la población provincial creció algo más del $100 \%$, mientras que en el mismo período la de San Rafael aumentó el 400 \%. Cabe señalar también el importante caudal inmigratorio que llegó al sur: en 1895 los extranjeros constituían aproximadamente un $16 \%$ en la provincia, y en San Rafael un $25 \%$, y en 1914 representaban alrededor de un $35 \%$ y más del 50\% respectivamente. La comunidad chilena, que era el grupo extranjero más importante antes de la colonización, quedó en segundo lugar luego de la española, y luego la italiana y francesa. 
justicia de paz se adecuó a los lineamientos señalados por las constituciones, las leyes orgánicas y los códigos vigentes en el período, dadas las particularidades de la institución y la lejanía de las instancias judiciales más altas, y si constituyó una instancia válida ante la cual pudieran resolverse los conflictos vecinales.

\section{LOS ANTECEDENTES: LA CONFIGURACIÓN LEGAL DE LA JUSTICIA DE PAZ MENDOCINA EN EL SIGLO XIX}

Según hemos comprobado anteriormente ${ }^{8}$, la organización de la justicia de menor cuantía en la provincia de Mendoza fue el resultado del cruce de diversas tradiciones. En los comienzos de la organización provincial habían ejercido la justicia local en la campaña unos jueces subdelegados creados en 1821 para el ejercicio de la $1^{\text {a }}$ instancia en villas con un cierto desarrollo poblacional. Estos magistrados reunieron otras importantes funciones, que quedaron diseñadas por el Reglamento de Estancias de 1834 y otra normativa que lo completó posteriormente: de policía rural, y municipales en las villas, de agentes del gobierno en las localidades, y la comandancia de Frontera en los lugares de confines con el indígena. Tal acumulación de facultades muestra su raigambre indiana, al estilo de los jueces comisionados nombrados con amplias atribuciones en el siglo XVIII, con la finalidad de consolidar núcleos de población rural y protegerlos de los avances indígenas. Esta característica se dio también en los funcionarios de menor jerarquía que dependían de aquéllos: los comisarios, creados por el Reglamento de Policía de 1828, y los decuriones, último eslabón del escalafón judicial y policial'. Fue a ellos a quienes el Reglamento de Administración de Justicia de 1834 les otorgó expresamente la función conciliatoria.

Dicha organización administrativa se mantuvo dentro de los cánones señalados hasta que en 1872 fueron creados los jueces de paz, quienes, a diferencia de los subdelegados, tuvieron exclusivas funciones judiciales, y es en este sentido que se adecuaban al principio de división de poderes. Con su creación les fueron retiradas las facultades judiciales a los subdelegados, quienes también perdieron las atribuciones municipales al crearse las municipalidades en 1868. Se trató de un período en que se dictaron varias leyes en orden a modernizar el Estado provincial, de acuerdo con las ideas de algunos hombres del partido liberal que gobernó en la provincia tras la derrota del federalismo en la batalla de Pavón 1861 . Si los subdelegados con sus connotaciones indianas habían sido considerados el instrumento necesario para la conservación del orden en la campaña en momentos

SAnjuRJo De Driollet, Inés, Frontera indigena y colonización agricola, en Richard-Jorba, Rodolfo y otros, La región vitivinicola argentina. Transformaciones del territorio, la economía y la sociedad, 1870-1914 (Buenos Aires, Universidad Nacional de Quilmes Editorial, 2006), pp. 243 ss.

${ }^{8}$ Sanjurjo, Inés Elena, Justicia de paz y cultura jurídica, cit. (n. 3).

${ }^{9}$ Estos últimos habían surgido como alcaldes de barrio o cuartel a fines del siglo XVIII, tomando la nueva designación a comienzos del siglo XIX. SAnjurjo De Driollet, Inés, Muy ilustre Cabildo Justicia y Regimiento. Estudio institucional del cabildo de Mendoza en el siglo XVIII (Mendoza, Facultad de Filosofía y Letras, UNCuyo, 2005). 
en que se impulsaba la ganadería para su comercio en Chile hacia los años de $1830^{10}$, en la década de 1870 se levantaron voces en contra de la concentración de funciones, por considerársela impropia del constitucionalismo liberal ${ }^{11}$.

Otra de las diferencias que presentaron los jueces de paz respecto de los subdelegados fue la capacidad menor que se les dio respecto de la que habían tenido éstos en materia de justicia. Además, como había querido Alberdi, quedaron dentro de la esfera de las municipalidades, siendo éstas las encargadas de designarlos y controlar el ejercicio de su función. La ley de 1872 dispuso que fueran legos, y que de sus fallos se apelase, a partir de un cierto monto, ante los jueces de $1^{\circ}$ instancia radicados en la ciudad, que eran letrados y entendían en causas de un importe mayor para toda la provincia.

Con esta norma la división de poderes abarcó también los estratos más bajos de la administración territorial. En efecto, comisarios y decuriones no fueron incluidos en la nueva organización, quedando por lo tanto sólo con las atribuciones policiales. Pero esto cambió en 1880, mediante la Ley Orgánica y de Procedimientos de la Justicia de Menor Cuantía que les otorgó nuevamente funciones judiciales de ínfimo monto. La vuelta a la acumulación propia del período indiano en estos estratos inferiores de la administración territorial muestra el peso de las antiguas prácticas de gobierno de las localidades. Sin embargo, cabe destacar que esta vez había actuado el impulso de nuevas corrientes de pensamiento, concretamente el organicismo krausista profesado por el Ministro de Gobierno Julián Barraquero. Inspirado en tales ideas, fue partidario de la autonomía municipal y de la descentralización, algo que se pensaba tendría un comienzo de cumplimiento con la aplicación de esta reforma de la justicia inferior. Un elemento descentralizador fue también la creación de Juris de apelación conformados por vecinos, los que constituirían el tribunal de alzada para los fallos de los jueces de paz, en tanto que éstos entenderían en las apelaciones de los fallos de comisarios y decuriones. Juris de apelación, jueces de paz, comisarios y decuriones, debían ser nombrados por la municipalidad del respectivo departamento, y gozarían de las inmunidades que tenían los jueces superiores. La ley disponía expresamente, por otra parte, la obligación de estos funcionarios menores de buscar entre las partes "concordia, conciliación, paz y arreglo", y sólo una vez agotados estos recursos debían dictar

${ }^{10}$ Sobre la economía mendocina en esta etapa, cf. Richard-Jorba, Rodolfo, Poder, espacio y economía en Mendoza, 1850-1900 (Mendoza, Facultad de Filosofía y Letras, UNCuyo, 1998).

${ }^{11}$ No obstante ello, durante el gobierno de Francisco Civit, se les otorgó nuevamente facultades municipales al establecerse por ley de 1874 que presidieran las municipalidades. Evidentemente no había homogeneidad de ideas en la elite, en cuanto al grado de autonomía que debían tener las municipalidades. Algunos, menos principistas y más pragmáticos, como Francisco Civit, consideraron que la institución comunal representaba un gasto, y que en ella los vecinos sólo se dedicaban a hacer política, a la vez que el dominio de las municipalidades por los agentes del Ejecutivo provincial favorecía el control político de las comunidades locales. SANJURJO DE DRIOLLET, Inés, La organización politico-administrativa de la campaña mendocina en el tránsito del antiguo régimen al orden liberal (Buenos Aires, Instituto de Investigaciones de Historia del Derecho, 2004). 
resolución "según su conciencia"12. Tanto el nombre justicia de paz, como la expresa función concilia to ria, encontraban influencias en la justicia de paz francesa, a la vez con vinculaciones con los “justices of peace" ingleses. La función conciliatoria, tenía, por su parte, antecedentes en el Derecho público provincial, y un ejemplo es el Reglamento de Administración de Justicia de 1834 citado $^{13}$.

A la confluencia de las diversas tradiciones señaladas, se sumó a fines del siglo XIX otra vertiente: la cultura del código y el positivismo jurídico. Precisamente, una novedad introducida en Mendoza a fines del siglo XIX fueron los Códigos de Procedimientos en materia Criminal y en materia Civil y Comercial, sancionados en 1894 y 1895 respectivamente. Ello fue parte de un proceso que abarcó a todas las provincias, que se vieron obligadas a actualizar su sistema procesal de acuerdo con los códigos civil, penal, comercial y de minería dictados en la esfera nacional a partir de $1869^{14}$. Los nuevos códigos de procedimientos reglamentaron el accionar todos los magistrados de la provincia, incluida la justicia de paz. Avanzaba el positivismo jurídico y con la codificación se implantaba "una tecnología normativa basada en la generalidad y en la sistematicidad”, y se aseguraba un mayor control por parte del Estado ${ }^{15}$.

${ }^{12}$ Mensaje del Gobernador Nicolás Godoy con motivo de la sanción de la Ley Orgánica y de Procedimientos de la Justicia de Menor Cuantía, Registro Oficial de Mendoza, 1880. Ya el Reglamento de Administración de Justicia de 1834 había dispuesto que los decuriones debían procurar conciliar amigablemente y sólo en caso de no conseguirlo, proceder a resolver lo que crea (n) justo. SANJURJO DE DRIOLLET, Inés, La organización cit. (n. 11).

${ }^{13}$ Sanjurjo, Inés Elena, Justicia de paz, cit. (n. 3); y Seghesso, M. Cristina, Historia Constitucional de Mendoza (Mendoza, Instituto Argentino de Estudios Constitucionales y Políticos, 1997).

${ }^{14}$ En la convención Constituyente de 1853 se impuso la tesitura de Benjamín Gorostiaga, quien sostuvo las ventajas de la uniformidad legislativa en lo relativo a la codificación, y que las provincias podrían decidir sobre sus respectivos procedimientos. Así, el artículo 64 inc. 11 de la Constitución Nacional sancionada ese año dictaminó que correspondía al Congreso dictar los códigos civil, comercial, penal y de minería, correspondiendo su aplicación a los tribunales federales o provinciales. Sin embargo, no se explicitó sobre los códigos procesales a dictarse por las provincias. TAU AnZOÁTEguI, Víctor, La codificación en la Argentina (Buenos Aires, Instituto de Historia del Derecho Ricardo Levene, 1977), pp. 348 s.

${ }^{15}$ Cf. Hespanha, Antonio, cit. (n. 6), p. 173. Por su parte, E. Abásolo ha considerado al código más que como el producto intelectual de uno o varios individuos, como el derivado de una cierta cultura jurídica, concepto, este último, bajo el cual entiende un vasto conjunto de conocimientos, valores, principios e ideologías compartidos que, vinculados con el derecho, imperan en una época y en un lugar determinados. La codificación sería así la peculiar expresión de la nueva forma mentis de concebir al derecho que se fue imponiendo en Occidente desde las postrimerías del siglo XVIII, en un particular clima ideológico -según terminología usada por Tau Anzoátegui- signado por el proceso de substitución de una cultura jurídica hasta entonces imperante, la antigua del ius commune por otra, la de la codificación, propia del racionalismo. AвÁsolo, Ezequiel, Las notas de Dalmacio Vélez Sársfield como expresiones del "ius commune" en la apoteosis de la codificación, o de cómo un código decimonónico pudo no ser la mejor manifestación de la "Cultura del Código", en Revista de Estudios Histórico-Jurídicos, 26 (Valparaíso, 2004). 


\section{Bajo la Constitución PROVINCIAL de 1900: LA "Ley orgánica de TRIBUNALES” DE 1900 Y SU ARTICULACIÓN CON LOS CÓDIGOS PROVINCIALES}

La Constitución de 1894/5 favoreció la autonomía municipal, conforme a lo establecido en la de 1854 y en consonancia con el organicismo de uno de sus inspiradores, Julián Barraquero. Con ese fin establecía expresamente que todos los miembros -se entiende incluido el presidente- debían ser elegidos por sufragio, y no por el Ejecutivo provincial ${ }^{16}$. En cuanto a los jueces de paz, esta carta fundamental les dedicaba un capítulo, en el que se disponía su establecimiento en toda la provincia de acuerdo con la extensión territorial y la población; debían saber leer y escribir, tener 25 años de edad y dos de residencia en el distrito. Vale decir que se buscaba que contasen con cierta cultura y arraigo en el lugar, aunque no se requería que fuesen letrados ${ }^{17}$. Una novedad era la intervención del gobernador en su elección, a propuesta en terna por la municipalidad. Tal injerencia, más allá de las consecuencias prácticas que pudo traer, no parece haber estado pensada estrictamente en términos de centralización, sino más bien como un intento de establecer una garantía más a fin de lograr la designación de magistrados idóneos ${ }^{18}$. Sin embargo, en el año 1900 se sancionó una nueva carta provincial, esta vez bajo el signo de la centralización impuesto por el civitismo ${ }^{19}$. Por ella se estableció que el presidente de la municipalidad sería elegido por el gobernador, de allí que ejercieran el cargo los agentes territoriales de éste, ahora denominados jefes políticos. En lo relativo a la justicia de paz, tal situación derivaba en una mayor dependencia respecto del gobierno provincial, puesto que los jefes políticos podían influir en la conformación de las ternas a presentar al Ejecutivo $\mathrm{y}$ en el control de su accionar ${ }^{20}$.

Una cuestión que ya estaba señalada en el Código de Procedimientos en materia Civil y Comercial bajo el título: Del procedimiento ante la justicia de paz, y que ratificó la Ley Orgánica de Tribunales de $1900^{21}$, es que esta justicia estaría a cargo

\footnotetext{
${ }^{16}$ En Constituciones de la Provincia de Mendoza hasta 1915 (Edición Oficial, Mendoza, 1915).

${ }^{17}$ Artículos 184 a 186 de la Constitución de la Provincia de Mendoza 1894/95, Archivo Histórico de la Provincia de Mendoza, Independiente, legajo 21, arpeta 26.

${ }^{18} \mathrm{La}$ Constitución de 1895 buscó que los cargos municipales estuviesen en manos de personas capaces, mediante limitaciones de tipo cultural y económico impuestas al sufragio en ese nivel de gobierno. Con ello se trataba de garantizar el buen uso de la autonomía que se otorgaba a las municipalidades. SANjurjo, Inés Elena, Justicia de paz y cultura jurídica, cit. (n. 3).

${ }^{19} \mathrm{La}$ reforma de 1900 fue promovida por el gobernador Emilio Civit (1898) quien renunció para hacerse cargo del Ministerio de Obras Públicas de la Nación, durante el gobierno de Julio A. Roca (1898-1904). No obstante, dejó trazado el camino para la reforma.

${ }^{20}$ No era un dato menor desde el punto de vista político, ya que los jueces de paz presidían las mesas inscriptoras para la formación de los padrones electorales, con lo que constituyeron un importante mecanismo de maniobra preelectoral.

${ }^{21}$ Las condiciones que debían reunir jueces de paz y decuriones estaban dentro de los cánones establecidos por la ley de 1872, aunque con mayores exigencias en cuanto a residencia en el departamento y condiciones morales y económicas. Ley orgánica de tribunales de $18 \mathrm{de}$ setiembre de 1900, Registro Oficial de Mendoza..
} 
de jueces de paz y decuriones, siendo estos últimos elegidos directamente por la municipalidad. Con ello desaparecían otras instancias en la administración de la justicia local: los jurados de apelación establecidos en 1872 y los comisarios, quedando éstos últimos sólo con funciones policiales y de auxiliar de justicia. Además de simplificarse la estructura judicial territorial se consolidaba la figura del juez de paz, tal como lo muestran las amplias atribuciones que se le concedían. En materia penal la ley de tribunales señalaba como de su jurisdicción los siguientes delitos: violación de prostituta, rapto con intención de casarse, amenazas y coacciones, descubrimiento de secretos, injurias leves, hurto o rapiña en no más de 50 pesos, usurpación, estafa, daños no superiores a 50 pesos, revelación de secretos y falso testimonio. Esta norma remitía, para la especificación de los mencionados delitos, al Código Penal de la Nación y establecía que en ningún caso podría imponer pena superior a tres meses de arresto $^{22}$.

En materia civil y comercial, dicha ley dispuso que los jueces conocieran en las apelaciones de las sentencias pronunciadas por los decuriones, en asuntos cuyo valor excediese los 10 pesos; entender en causas de un monto de entre 20 y 200 pesos; en juicios de sucesión cuando el caudal inventariado no excediese los 1000 pesos, siempre que no se suscitase ninguna cuestión sobre la calidad de los herederos; y en juicios de desalojo de casas o de predios urbanos ${ }^{23}$. Los pasos a seguir en los juicios relativos a estas cuestiones, eran los estipulados en el Código de Procedimientos de $1895^{24}$ : juicio verbal, salvo en las causas sucesorias y de concurso de acreedores en que debía ser por escrito: "No se admitirá escrito alguno ante la justicia de paz. Todo el juicio se hará constar en actas firmadas por el juez, de las cuales se formará un legajo foliado". Las sentencias definitivas debían copiarse en un libro especial debiendo ser suscriptas por el juez, y en donde también había que copiar las de segunda instancia ${ }^{25}$. La solicitud del demandante tenía que hacerse con los debidos fundamentos adjuntando solicitud de citación a la persona demandada, ante lo cual el juez debía fijar día y hora para que ambas partes compareciesen a escuchar y contestar respectivamente. Dicha exposición tenía que constar en un acta firmada por el juez de paz y el actor. Se estipulaba, además, sobre la citación del demandado por parte del juez -si no se declaraba incompetente para resolver el caso- mediante una cédula con los datos de demandante y demandado, motivo de la demanda y día y hora de la cita; la publicación de edictos de citación en la puerta del juzgado en caso de ausencia del demandado; el plazo de tres días entre la citación y el juicio; la dinámica de la audiencia; la continuación del juicio en rebeldía, si el demandado no se presentaba luego de determinada cantidad de días $^{26}$; la actuación de un defensor especial en cuestiones relativas a menores y

${ }^{22}$ Ibíd.

${ }^{23}$ Ibíd.

${ }^{24}$ Código de Procedimientos en materia Civily Comercial de la Provincia de Mendoza, 1895. Compendio de Leyes usuales de la Provincia. Con todas la modificaciones introducidas hasta el 31 de diciembre de 1924 (Buenos Aires: G. Kraft Impresora, 1925), XVIII.

${ }^{25}$ Ibíd., artículo 542; y artículo 17 de la Ley orgánica de tribunales de 18 de setiembre de 1900, cit. (n. 21).

${ }^{26}$ Se consideraba rebeldía si no se presentaba luego de 20 días de la publicación de la 
de pobres y ausentes; y la representación de apoderados o representantes de otro en el juicio.

Un aspecto en el que este Código había sido explícito, a diferencia de la Ley orgánica de tribunales, fue el conciliatorio: previamente al fallo, el juez, ya impuesto de lo que pretenden las partes, debía procurar que se arreglen y terminen sus diferencias, ayudándolas con toda imparcialidad. Sólo luego, "si los litigantes no se arreglan y están conformes con los hechos alegados en la demanda y en la contestación, el juez dará sentencia en el mismo acto si fuera posible, y en caso contrario dentro de cinco dias emplazando a las partes para que comparezcan a oír sentencia ${ }^{227}$. Sin embargo, en caso de desacuerdo con lo expuesto por la parte contraria, se debía poner fecha de no más de 10 días para presentar nuevas pruebas, ante lo cual sólo entonces los jueces debían fallar.

La etapa verbal ciertamente preveía la agilidad del proceso que tradicionalmente fue atribuida por la doctrina a esta magistratura, pero la obligación de formar un expediente con las actas firmadas por el juez y por las partes -y por los testigos cuando los hubiere-, y de asentar posteriormente las sentencias en un libro especial, parecía contrariar aquel objetivo, de igual modo que el requisito de consultar los códigos. Sin embargo, los plazos impuestos para la substanciación de los juicios eran $\operatorname{cortos}^{28}$ y el cumplimiento del trámite escrito ciertamente contribuiría a garantizar un mayor control de la actuación del magistrado y asimismo constituiría una garantía para las partes.

Por otra parte, si bien había una mayor reglamentación en lo procedimental debido a la sanción de los códigos, lo cual parecía atenuar el concepto de juez de mera conciencia, sólo debía respetarse la ley en cuanto le fuera posible al juez: "Los jueces de paz fallarán conforme a su leal saber y entender y de acuerdo con lo alegado y probado por las partes, procurando en cuanto sea posible ajustar sus sentencias a derecho" ${ }^{29}$.

\section{La Constitución de 1910 y la “Ley ORGÁnica de tribunales” Nº 552}

La Constitución de 1910, que rigió hasta 1916, se destacó por lo escueto de

citación en periódicos -en caso de no conocerse su domicilio-; a la vez se establecía que si se ubicaba su paradero, debían mediar al menos 3 días desde la citación. Artículos 547 y 554 , Código de Procedimientos, cit. (n. 24).

${ }^{27}$ Ibíd., artículos 544-554.

${ }^{28}$ Entre la citación y el juicio debían mediar por lo menos tres días, y si no se conocía el domicilio del demandado, aquélla debía publicarse tres veces en el periódico local, no debiendo pasar la fecha de la audiencia de los veinte días de publicada. Producida la audiencia, si el juez no lograba el acuerdo entre las partes, debía fallar en ese mismo acto si fuese posible, y no más de cinco días después. Si las partes alegaban hechos controvertidos, debía declarar el pleito a prueba, lo que no podía ser en un tiempo mayor de diez días si era ante el decurión, y de veinte si lo era ante el juez de paz, prorrogándose a más días a mayor distancia en que se hallaba la prueba. Si todos los testigos no pudiesen comparecer en un mismo día, se les debía tomar declaración lo más pronto posible. Vencido el período a prueba, el juez debía fallar dentro de los diez días. Artículos 547 a 565, Código de procedimientos en materia civil, cit. (n. 24).

${ }^{29}$ Artículo 574, Código de Procedimientos en materia Civil, cit. (n. 24). 
sus disposiciones, contrariamente al excesivo reglamentaris mo de la de $1900^{30}$. En materia municipal, la novedad fue la introducción del municipio urbano o municipio-villa, que limitaba el gobierno comunal a los núcleos poblacionales, dejando de lado el municipio de amplio territorio impuesto desde $1854^{31}$. Se dijo en la convención que había que dar fomento a los nuevos pueblos que habían ido surgiendo en la campaña, muchos de ellos en torno a las estaciones del ferrocarril ${ }^{32}$, cuyo recorrido había llegado hasta San Rafael en 1903. Esto no significaba, sin embargo, que se otorgara una mayor autonomía a esos órganos de gobierno local, puesto que se dispuso la elección de las autoridades a cargo del Ejecutivo provincial.

Respecto de la justicia de paz, esta Constitución no toca el tema, por lo que su organización fue realizada por la Ley orgánica de tribunales $\mathrm{N}^{\circ} 552$ sancionada también en $1910^{33}$. Esta norma introdujo variaciones, entre ellas, la expresa disposición de que quedara a cargo de Jueces de Paz y suplentes de éstos, con lo cual desaparecía la figura de los decuriones luego de más de un siglo de vigencia. Sí, en cambio, se habla de unos jueces de cuartel, los comisarios y subcomisarios, según una estructura que prefiguraba la actual organización policial de la provincia ${ }^{34}$. A éstos se atribuyó la capacidad de dirimir en asuntos de ínfima cuantía -hasta 20 pesos-, en los desalojos de piezas de conventillos y en los llamados ranchos, debiendo "proceder en forma rápida resolviendo las cuestiones con equidad, trasladándose al domicilio de las partes si fuera necesario, labrándose acta de la resolución final". En los cobros de alquileres, si no lograban un arreglo debían trabar embargo y pagar la deuda con lo obtenido de la venta ${ }^{35}$. Se debe tomar nota de que únicamente para esta cuestión la ley habla de arreglo, quedando la función conciliatoria es-

${ }^{30}$ Cf. Constituciones de la Provincia de Mendoza, cit. (n. 16).

${ }^{31}$ Egües cita entre las principales novedades de esta constitución las relativas a derechos sociales, sostenimiento del culto católico, reducción del número de disposiciones, extensión del período del gobernador, elección directa de diputados y senadores, movilidad de los jueces y requisitos para la reforma constitucional [EGÜEs, Carlos, Historia constitucional de Mendoza. Los procesos de reforma (Mendoza, Ediunc, 2008), pp. 60 s.]. Por nuestra parte, consideramos digna de mención también la cuestión de la fijación del radio municipal, puesto que la carta de 1910, contrariamente a la tradición de municipio de amplio territorio inaugurada en 1854 y aún hoy vigente en Mendoza, estableció el municipio urbano por un breve período en la provincia, de igual modo que la peronista de 1949.

32 "Libro de Actas de la Convención Constituyente de la Provincia de Mendoza" de 1908. Archivo de la Legislatura de la Provincia de Mendoza.

${ }^{33}$ Ley orgánica de tribunales $\mathrm{N}^{\circ} 552,1910$, en Recopilación de Leyes desde el $1^{\circ}$ de enero de 1896 al 31 de diciembre de 1924 correspondientes al Ministerio de Gobierno (Mendoza, 1925), III, pp. 958 ss.

${ }^{34} \mathrm{La}$ organización policial se basa actualmente en lo que Adolfo Posada llamó el "principio de unidad funcional» de la policía, como precepto doctrinario contrario a la separación de funciones de seguridad y judiciales. Posada fundamentó su tesis en la influencia definitiva del derecho administrativo francés y la ciencia de policía de este mismo origen. TiscorniA, Sofía, Entre el imperio del "Estado de Policía" y los limites del derecho, en Nueva Sociedad 191 (Buenos Aires, mayo-junio de 2004), pp. $80 \mathrm{~s}$. Creemos, por nuestra parte, que esta "unidad funcional" en la policía muestra también elementos en común con los funcionarios inferiores de la administración indiana y sus continuidades en el siglo XIX.

${ }^{35}$ Título X: De los jueces de cuartel, en Ley orgánica de tribunales $\mathrm{N}^{\circ}$ 552, cit., p. 963 s. 
tablecida para los jueces de paz en el Código de Procedimientos en materia Civily Comercial todavía vigente.

Otra innovación radicaba en que no se mencionaban dentro de las atribuciones de los jueces de paz asuntos en materia penal, en tanto que su competencia en materia civil o comercial era actualizada a un monto de entre los 20 y 500 pesos. Podían entender también en juicios de sucesión y de concurso civil de acreedores hasta 1000 pesos, si no se suscitaba ninguna cuestión sobre la calidad de los herederos; en casos de desalojo de un canon mensual hasta 200 pesos; en faltas de respeto a su autoridad por multas no mayores de 15 pesos; en juicios por vía de apremio por cobro de impuestos municipales, fiscales o multas, cualquiera fuera la cantidad a cobrar; y en cuestiones de herencias de desconocidos, en las que debían hacer inventario y tomar las medidas de conservación indispensables ${ }^{36}$.

Los jueces de paz continuaban con la condición de $\operatorname{legos}^{37}$ y su elección quedaba en manos del Ejecutivo de una terna presentada por las municipalidades, aunque se impuso un mayor control del Poder Judicial, pues debían aprobar un examen ante la Corte. Con ello se procuraba que demostraran capacidad para el cargo aunque no fuesen letrados. Además, el libro de sentencias debía tener sus folios sellados por la Suprema Corte y contar con una constancia del número de páginas firmada por el presidente de este alto organismo, contribuyendo con ello al mayor control por parte del Poder Judicial.

La Constitución de 1910 fue modificada por la de 1916, que es la que rige actualmente en la provincia, y que, entre otros cambios, dispuso la dependencia directa del Poder Judicial. La participación de las municipalidades en la elección y control de la justicia de paz -concretamente por parte de los concejos, elegidos por sufragio popular- hacía a la inmediatez con la comunidad local que se pretendía para dicha magistratura ${ }^{38}$, principio que esta vez era dejado de lado. Desde 1916, la Suprema Corte de Justicia de la Provincia fue la que debió proponer la terna de

\footnotetext{
${ }^{36}$ Artículo 118: "En ningún caso será atribución de los Jueces de Paz, conocer en los juicios sobre sucesiones vacantes o cuando los herederos sean desconocidos o estén ausentes; cuando se trate de autorizar documentos públicos [...] protocolizar documentos públicos o abrir los testamentos cerrados. No pueden tampoco intervenir en las causas de filiación, matrimoniales, juicios de mensura o deslinde, nombramientos de tutores, curadores y demás actos de jurisdicción voluntaria, no debiendo considerarse excluida de su jurisdicción la facultad de nombrar tutores y fiscales en los asuntos de competencia ni la de colocación provisoria de los menores abandonados, con cargo de dar cuenta inmediatamente, en este caso, al Defensor de Menores": Ley orgánica de tribunales No 552, cit. (n. 33).

${ }^{37}$ Para ser juez de paz titular o suplente se requería ser ciudadano argentino, con dos años de residencia inmediata en la Provincia, cuando no sea nacido en ella; tener veinticinco años de edad; estar en pleno goce de su capacidad civil; no haber sido condenado por algún delito y tener la aprobación de examen de competencia ante la Suprema Corte, según programa que se confeccionará (ibíd., artículo 108).

${ }^{38}$ Tomás Bernard - de la escuela municipalista de La Plata, sustentadora de la teoría de república representativa municipal iniciada por Adolfo Korn Villafañe-sostiene que la justicia de paz o de menor cuantía, "por lo general lega, de carácter patriarcal, administrada como lo haría un buen padre de familia, es típicamente municipal”: BERnARD, Tomás, Régimen municipal argentino. Origen institucional y su evolución hasta la época actual (Buenos Aires, Depalma, 1975), p. 102.
} 
candidatos al Ejecutivo, acorde con la mayor intervención que aquel Poder venía teniendo en diversos aspectos de la institución. Hay que aclarar que no obstante este recorte de atribuciones, en 1916 las municipalidades recobraron la autonomía que les había otorgado la carta de 1895 , y anteriormente la de 1853 en cuanto a la elección popular de todos sus miembros.

\section{LAS PRÁCTICAS EN TORNO A LA JUSTICIA DE PAZ en el Sur de la provincia de Mendoza}

Una vez avistada la configuración legal de la institución, examinaremos algunos expedientes que consideramos representativos de las prácticas institucionales en torno a los asuntos en materia civil y comercial. Es precisamente el estudio de las prácticas institucionales lo que nos permite no sólo comprobar la vigencia de la norma escrita, sino también constatar la dinámica interna de las instituciones, a la vez que puede brindar la posibilidad de advertir si la repetición de usos en sus procedimientos dio lugar a alguna forma de normativa paralela a la establecida por la ley ${ }^{39}$.

Hemos seleccionado algunos casos que nos permiten avanzar en la caracterización de la justicia de paz mendocina de principios del siglo XX, los cuales pertenecen al juzgado de paz de la Villa 25 de Mayo del departamento de San Rafael. La creación de juzgados debía hacerse de acuerdo con el crecimiento poblacional, y en el caso de San Rafael, la mencionada villa había sido la cabecera departamental, surgida al amparo del fuerte creado en 1806 y sede de las autoridades, entre las cuales se contaba a fines del siglo XIX el juzgado de paz. Al trasladarse la cabecera a Colonia Francesa en 1903 -debido al acelerado progreso de las nuevas poblaciones- se le dio a ésta el nombre de Villa de San Rafael, radicándose allí otro juzgado ${ }^{40}$. Era por entonces el único departamento con dos juzgados de paz.

Los expedientes muestran, en general, que las causas penales se iniciaban con un sumario instruido a acusados y testigos por el comisario del lugar donde había ocurrido el hecho delictivo. Las declaraciones, asentadas en un formulario impreso, según consta en los expedientes correspondientes a esta materia, eran luego elevadas al Jefe Político, quien las derivaba al juzgado de paz juntamente con el detenido, si lo había. Los que llegaban a las manos del magistrado eran delitos consistentes en hurtos, injurias y heridas y muchos de estos últimos se debieron al consumo de alcohol ${ }^{41}$. Fueron tales casos los que tuvieron repercusión en la

${ }^{39}$ Cf. Hespanha, Antonio, Visperas del Leviatán. Instituciones y poder politico. Portugal, siglo XVII (Madrid, Taurus, 1989).

${ }^{40}$ Este criterio siguió aplicándose con el tiempo en toda la provincia, así por ej. por un decreto del Poder Ejecutivo provincial de 1911 se creó un juzgado de paz en Las Catitas, del Departamento de Santa Rosa, dado que "vendría a llenar una sentida necesidad por el desarrollo de ese distrito y la distancia a que se encuentra de la cabecera departamental, donde se encuentra el actual juzgado" (Decreto del 2 de septiembre de 1911, Registro Oficial de Mendoza).

${ }^{41}$ Según se desprende de la lectura de los expedientes de Justicia de Paz en materia penal, que obran en el Archivo Judicial de San Rafael. 
prensa local. Así, por ejemplo, en la sección Policiales del periódico San Rafael, se dijo que muchos son los desórdenes, bochinches, camorras y escándalos en general que están produciéndose por causa del abuso del licor. Se refería a los hechos de sangre que ocurrían con frecuencia por obra del alcohol, y en esa oportunidad, se atribuía a los linieros o trabajadores de la línea del ferrocarril ser los autores de la mayor parte de los delitos ${ }^{42}$.

No comenzaban de igual forma las causas en materia civil. Era la presentación de una demanda ante el juez de paz, realizada por un particular o por una empresa o entidad de gobierno - tal el caso por cobro de deudas fiscales- o por su apoderado, la que solía originar los juicios. Esta demanda era recogida en un acta firmada por el magistrado - tal como lo disponía la legislación- y por el demandante o un testigo si éste no sabía firmar, como ocurría frecuentemente. Una gran cantidad de expedientes sólo constan de la demanda y la citación de actor y demandado para exponer sus puntos de vista. Esto puede sugerir que en esa primera audiencia se llegó al acuerdo o conciliación, que era lo primero que debía buscar el juez, de allí que no fuesen necesarias otras citaciones, ni la presentación de pruebas y el fallo ${ }^{43}$. Puede conjeturarse que una vez logrado el arreglo, no se levantaba el acta correspondiente debido a dejadez del juez. Pero, por otra parte, como comenta Darío Barriera a propósito de un trabajo anterior nuestro sobre la justicia de paz, si las leyes promovían y pretendían la conciliación como tarea preferente del juez de paz, y los registros escritos testimonian escasas situaciones expresamente asentadas en ellos, "es ciertamente posible que los jueces desarrollaran una actividad de conciliación que pudo haber escapado a los registros; sin embargo, hay motivos para pensar que si su intervención en este rubro era requerida por la ley, tenían buenas razones para dar cuenta de este tipo de acciones aunque fuera de manera sumaria" ${ }^{44}$.

Existen también evidencias de que en muchas ocasiones los juicios no lograron ese primer objetivo, y por tal motivo se continuaba con los pasos mencionados, llegándose al veredicto o sentencia del juez, y pudiendo culminar con embargo de bienes y ejecución. Este proceso requirió de un conjunto de auxiliares que trajinaban en torno al juzgado, tales los oficiales de justicia, que se encargaban de notificar las providencias del juez de paz, muchas veces en otros poblados; los decuriones de los distritos más lejanos, que cumplían igual misión en esos lugares; los apoderados o procuradores, nombrados por escrito para representar a alguna de las partes; los peritos, autorizados para realizar inspecciones “oculares" y dar un dictamen sobre la cuestión de que se trataba, etc.; tareas en las que a veces se alternaban los mismos individuos y por las que cobraban una suma determinada.

Un dato central es que la mayoría de los expedientes encontrados tienen como

${ }^{42}$ San Rafael, Mendoza, 30 de setiembre de 1903.

${ }^{43}$ No disponemos del libro de sentencias que reglamenta el artículo 17 de la Ley de Tribunales de 1900, y por lo tanto no podemos constatar si tales juicios continuaron más allá de la demanda y terminaron en fallo, lo que nos hablaría de un extravío de fojas.

${ }^{44}$ Barriera, Darío G., Justicias, jueces y culturas jurídicas en el siglo XIX rioplatense, Nuevo Mundo Mundos Nuevos (Debates, 2010, puesto en línea el 23 marzo 2010. URL : http:// nuevomundo.revues.org/59252. Consultado el 23 abril 2010). 
causa el quebrantamiento de acuerdos comúnmente verbales. Esto condice con el monto en litigio, que era, según lo establecía la ley, menor que el de los juicios substanciados en los juzgados de $1^{\circ}$ instancia con asiento en la capital de la provincia, los cuales, precisamente por las sumas mayores que se disputaban, se referían a contratos comúnmente asentados en los protocolos notariales ${ }^{45}$. Interesa conocer, entonces, qué valor tuvo la palabra, es decir qué obligaciones pudieron generar los acuerdos verbales; si los vecinos encontraron en el juzgado de paz un espacio de resolución de los conflictos relacionados con esos contratos-originados ya fuera por mala voluntad o por malentendidos que podían derivar precisamente de su carácter de verbales-, y en tal caso, qué tipo de pruebas pudieron hacer valer las partes en defensa de sus derechos y cuál fue el rol cumplido por ese juzgado.

El expediente caratulado "Tomás Lucero contra Luisa Jiménez por falta de cumplimiento de contrato", de 1904, trata de un compromiso de venta de un terreno, sin que mediara escritura sino sólo una promesa verbal por parte de la demandada, como expresamente se dice en el expediente. En virtud de ello, el actor había hecho mejoras y siembras en el referido inmueble y, como no obstante ello la demandada pretendía venderlo a otro interesado, Lucero solicitaba se la intimase a pagarle las tareas por él realizadas. El expediente consta sólo de esta presentación, pudiéndose presumir, como se ha dicho, que se logró la conciliación entre las partes ${ }^{46}$.

Otro ejemplo de contrato verbal, esta vez de compraventa, fue el realizado por Eliseo Flores y Alejo Barzola, en el que el primero fió al segundo un carro y 12 mulas de trabajo, por un valor de 600 pesos a pagar por éste, entregando 100 pesos por vez, en un plazo no mayor de 18 meses. Ante el incumplimiento de lo pactado, Flores se presentó ante el juzgado en septiembre de 1904, para exponer sobre la cuestión, solicitando que se citase a Barzola a una audiencia con el objeto de regularizar el contrato o anularlo. Este expediente también acaba en la presentación.

Un juicio originado por incumplimiento de un contrato verbal, y que nos muestra los pasos que se seguían en caso de no lograrse la conciliación, es el originado con la reclamación presentada el 22 de diciembre de 1911 por Doña Eloísa Fuentes "argentina, mayor de edad, quien expuso que con fecha 18 de junio

\footnotetext{
${ }^{45}$ Entre los contratos asentados en los protocolos notariales de San Rafael pueden mencionarse los de los "contratistas de plantación, que dieron comienzo, desarrollaron y consolidaron la viticultura capitalista en la provincia". Eran una de las formas mediante las cuales los propietarios ponían sus tierras en producción, ya que los contratistas se hacían cargo de la siembra de diferentes cepajes, aunque también los hubo "de mantenimiento o de viña, mixto y de trabajadores". La protocolización de los contratos muestra el interés del propietario por no resultar defraudado, pero también el del contratista, puesto que se estipulaba el pago que recibiría, que muchas veces consistió en un inmueble con hipoteca hasta la culminación del contrato. CANTARelli, Andrea, Contratistas de plantación: agentes geográficos en los comienzos de la viticultura moderna en San Rafael, Mendoza, 1880-1914, en Anuario del Centro de Estudios Históricos "Prof. Carlos S. A. Segretti", 9 (Centro de Estudios Históricos, Córdoba. ISSN 1666-6836), en prensa. Se agradece la gentileza de la autora.

${ }^{46}$ Éste, como todos los expedientes que se citan a continuación, pertenecen al Archivo de la Circunscripción Judicial de San Rafael, Provincia de Mendoza.
} 
celebró un contrato con Dn. Ramón Vidal, por el cual ella dio por adelantado [en arriendo] una casa y sitio de su propiedad ubicado en esta localidad'. Por el contrato la propietaria buscaba realizar mejoras en su finca, mediante el compromiso de Vidal de hacer "una pieza de $7 m$ por $4 m$ y su respectiva estufa, una cocina, ambas habitaciones de material y cimiento de piedra, llaneo y embarre general, y un gallinero", que debían estar terminados al año y medio de estar el hombre en posesión de la casa. Pero según la exposición, el demandado no sólo no había cumplido, sino que además había deteriorado las habitaciones existentes, cortado árboles y dejado los caballos sueltos dentro del sitio. En vista de ello, solicitaba la rescisión de lo acordado y el pago de alquiler por el tiempo de ocupación de la propiedad en cuestión, todo lo cual constó en un acta que fue rubricada por el juez de paz, y no sabiendo firmar, un testigo lo hizo por ella. La audiencia a la que fueron citados a comparecer las partes se realizó el 27 de diciembre, y siendo controvertidos los hechos alegados -es decir que no se llegó a un arreglo entre las partes-, se abrió la causa a prueba para el 31 de diciembre. Esta segunda audiencia fue pasada al 5 de enero por ser feriado el 31, y en la oportunidad la actora presentó el pliego de posesión del sitio y cuatro testigos con el correspondiente interrogatorio a realizarles: i) "Si Ramón Vidal, actual ocupante de la casa de Da. Eloisa Fuentes, ha cortado algunos árboles de la propiedad, y a más arruinado la casa y sitio de que se trata"; ii) "Si le consta que cuando Ramón Vidal recibió la casa, ésta se encontraba en buenas condiciones, como así todo el sitio"; y iii) "Cuánto vale a su juicio el alquiler mensual de la casa y el sitio".

Luego de que éstos respondieran -como era de esperar, de modo afirmativo a las dos primeras preguntas, y estimativamente a la última-, declararon dos testigos del demandado. Éstos expusieron, en términos generales, que Vidal había cortado menos árboles que los mencionados por la actora, que la casa estuvo siempre en las mismas malas condiciones, y que no conocían cuál podía ser el monto del alquiler. Acto seguido, vistos "los antecedentes que obran en el presente expediente", en el que "Eloisa Fuentes ha demandado a Dn. Ramón Vidal por rescisión del contrato y por el pago de daños y perjuicios y alquileres" -los que entendía sumaban unos 200 pesos- y teniendo en cuenta que "citados debidamente no se han arreglado, y abierta la causa a prueba, se desprende que el demandado no ha cumplido", tanto por la declaración de los testigos como por la vista ocular; es decir, en atención a haberse efectuado los pasos previstos por la ley para dictar sentencia, el juez dio su fallo. Por éste se obligaba a Vidal a pagar a Fuentes una suma en concepto de daños y perjuicios y alquileres, puesto que se había probado "ser muy equitativo el cobro". Dispuso también la rescisión del contrato y la entrega de la propiedad bajo apercibimiento de embargo y ejecución. Vidal fue notificado del fallo el 8 de enero de 1912, pero no quiso firmar, según consta ante testigo. El 17 de enero, en razón de que no había saldado la deuda -evidentemente ya había hecho entrega de la propiedad- la actora solicitó el embargo de los bienes del demandado, a saber: dos yeguas, un potrillo y una chancha con cuatro chanchitos. Días después la mujer pidió una ampliación a una cantidad de ladrillos, con el fin de alcanzar a cubrir el monto adeudado. Ambos reclamos fueron aprobados por el juez, ha- 
ciéndose efectivo el último de ellos el 7 de marzo, mediante el embargo de una cantidad de 2.500 ladrillos.

Hemos consignado las fechas, porque nos ha interesado conocer los tiempos en que se substanció el juicio: entre el 22 de diciembre de 1911 y el 7 de marzo de 1912, incluyendo la demanda, la primera audiencia en que las partes pudieron exponer sus puntos de vista y tratar de llegar a un acuerdo, otra audiencia en la que declararon los testigos de ambas partes y en la que el juez dio el fallo ( 5 de enero), el plazo para la observancia de la sentencia y el embargo de bienes ante el incumplimiento de la misma. El lapso transcurrido entre el inicio del expediente y la ejecución da, sin duda, la pauta de una rápida y eficaz resolución del litigio, esta vez por sentencia del juez.

Por otra parte, el juicio al que acabamos de referirnos es demostrativo del alcance jurídico que tenía la palabra en los acuerdos verbales, los cuales constituyeron el instrumento usado para mejorar o poner en producción las pequeñas propiedades. Solía ocurrir que una de las partes concurría con su propiedad y la otra con su trabajo, tal el caso que motivó el juicio iniciado por Dn. Tolentino Funes contra Dn. Antonio Di Fiori el 30 de mayo de 1903. Ambos habían acordado que el primero trabajara en dos terrenos de posesión del segundo, realizando una sementera en uno de ellos, y un potrero de alfalfa en el otro y que luego se repartiera el producido. Sin embargo, una vez realizada la cosecha surgieron disidencias por el monto que debía obtener cada uno, por lo que el propietario no hizo ningún pago. Así, "no siéndole posible ningún arreglo amistoso", Funes se presentó ante el juzgado para pedir solución a su problema. Inmediatamente se hizo presente Di Fiori "para ponerse a derechas con Tolentino Funes en demanda por cumplimiento de un convenio entre ambos". En una nueva audiencia, en que ambos comparecieron, el juez determinó que se diera lo obtenido en partes iguales después de sacar lo que le correspondía al trillador. Así, las disidencias surgidas por falta de entendimiento acerca de un contrato del que no quedaba evidencia escrita, fueron resueltas mediante un fallo que solucionó el conflicto en el plazo de tres días. La rapidez con que se expidió la justicia sin duda contribuía no sólo a restablecer el entendimiento entre los vecinos sino también a evitar que en casos como éste se perdiera el producto de la tierra.

Muchos de esos acuerdos se referían a cuestiones laborales, tal como lo muestra el expediente al iniciado con la presentación de Miguel Rodríguez, español, mayor de edad. Éste, "fijando domicilio en casa de Doña Visitación Pérez viuda de Varas, expuso que habiendo trabajado a Abdón Tala [de quien no consta la nacionalidad] catorce días y medio en trabajos de albañilería en la propiedad de éste, a razón de 4 pesos por día, lo que hace la suma de 58 pesos, de la que tiene recibida la cantidad de 23 pesos con 50 centavos"; y dado que Tala le era deudor de la suma de 34,50 pesos, los que se negaba a pagar, venía $a$ demandarlo. De acuerdo con la rapidez que indicaba el procedimiento a seguir, en la misma fecha se dio por recibida la demanda y se citó a las partes a una audiencia al tercer día hábil después de notificado el demandado, a objeto de reproducir y contestar respectivamente la demanda. Debido a que en esta oportunidad las partes alegaron hechos contro- 
vertidos, el juez decidió abrir la causa a prueba durante diez días, plazo en el que cada uno podía presentar testigos y evidencias ${ }^{47}$.

Finalmente el 28 de marzo, dado "que citados debidamente comparecen y no se arreglan; que abierta la causa a prueba el actor presentó pliego de posiciones"; que Tala a su vez presentó un comprobante de pago realizado a Rodríguez; y que éste al negarse a firmar reconocía tácitamente que la firma del recibo era la suya, el juez determinó, de acuerdo con el artículo 686 del Código Procesal Civil y Comercial, que quedaran "cancelados actor y demandado con los gastos como se han efectuado". Nótese que es un recibo firmado el que ha servido como comprobante del pago realizado, vale decir que la evidencia en este caso va más allá del testimonio verbal, pues es un documento escrito y rubricado por quien ha percibido el pago. En la fundamentación del fallo, el juez trajo a colación un artículo del Código Procesal que si bien no trata específicamente sobre los recibos de pagos, sino sobre la ejecución de bienes adeudados, le venía bien: "reconocida la firma de un documento de obligación, queda preparada la acción ejecutiva, aunque se niegue su contenido". Dado, pues, que en este juicio el demandante no quiso firmar para que se comprobase si la rúbrica del recibo era la suya, el magistrado dio por entendido que tácitamente reconocía que lo era, motivo por el cual consideró que la deuda estaba saldada. No conforme, el 31 de marzo Rodríguez se presentó ante el juzgado para manifestar su voluntad de apelar ante el superior tribunal. Sin embargo, el juez resolvió no dar lugar a lo solicitado por tratarse de un juicio de menor cuantía. En efecto, la ley establecía que sólo excediendo los 50 pesos eran apelables las resoluciones de los jueces de paz ${ }^{48}$. La solución del caso se logró, como puede verse, en el breve plazo de once días, en el que se produjo la presentación de testigos y pruebas, el intento de conciliación y el fallo del juez.

Sin embargo, podemos citar un expediente que tuvo que esperar bastante tiempo para ser archivado. El mismo estuvo motivado por la falta de cancelación de unas deudas de almacén, a las que se sumaron otras en concepto de inquilinato y otros servicios. El mismo se inició por demanda realizada el 27 de octubre de 2007 por Da. Adela Fuentes contra Dn. Eusebio Ruiz, "de 25 años, casado, domiciliado en esta localidad”, por un saldo de 93,25 pesos. Como prueba presentaba una cuenta o factura no firmada por el deudor, por un total de 160,55 pesos en concepto de pensión por cuatro meses concerniente al demandado, más la correspondiente a un peón de éste por el tiempo de un mes; lavado de ropa varias veces entre enero y julio; mercadería (harina, yerba, ginebra, café, azúcar, etc.) y préstamos de dinero en efectivo. El demandado, que estaba presente, expuso que no reconocía la deuda tal como estaba consignada, y presentó una cuenta por 79,40 pesos por mercadería suministrada a la demandante, y otra por 201 pesos en concepto de trabajos y otros servicios que le habría realizado: sueldo correspondiente a 20 días de trabajo de un peón y diversas tareas tales como talar álamos, cortar madera, arreglar una silla hamaca, dos viajes en coche hasta Colonia

${ }^{47}$ Como máximo, la presentación de pruebas ante los juzgados de paz debía llevar 20 días, aunque el juez podría establecer un plazo menor y luego a pedido, extenderlo: Código de Procedimientos en materia Civil, cit. (n. 24).

${ }^{48}$ Artículo 14, Ley de tribunales de 18 de septiembre de 1900, cit. (n. 21). 
Francesa, labranza y colocación de una solera, ventana nueva y marco de puerta, etc. Esta deuda no fue reconocida por la demandante, y como no hubo arreglo, el juez decidió abrir la causa a prueba, todo lo cual constó en un acta firmada por el magistrado y los litigantes.

El jueves 2 de noviembre la mujer solicitó que se hiciese comparecer a Ruiz a fin de responder, previo juramento de ley, si le constaba ser cierta la cuenta presentada por ella. El demandado declaró ese mismo día, diciendo que no le correspondía cumplir con el juramento, y en cuanto a la cuenta, esta vez manifestó su desacuerdo con algunos montos -como el de una deuda por comida- aunque aceptó un saldo a favor de la actora. El miércoles 8 nuevamente se presentó ésta con dos testigos, un jornalero de 23 años, soltero y domiciliado en la localidad, y otro, un hombre de 40 años, casado, chileno y residente en el distrito de Colón. Ambos, luego de prestar juramento y manifestar que no les correspondían las generales de la ley, confirmaron el precio convenido y que no había sido Ruiz sino el segundo de ellos quien había cordado los árboles y enmaderado la casa.

El 22 de ese mes, al finalizar el período de 20 días hábiles establecidos por la ley para la presentación de pruebas, se apersonó Ruiz para pedir prórroga y al mismo tiempo tachar la testificación por no habérselo convocado a presenciar el acto. Se basaba, aunque no lo citaba, en el art. 562 del Código que establecía la publicidad de toda prueba y la citación previa de la contraparte. Ante esto, Adela Fuentes expuso que la norma era terminante en cuanto al período de prueba, como dispone el artículo 556 del Código de Procedimientos en materia Civily Comercial de la Provincia ${ }^{49}$, y que los testigos fueron presentados por ella dentro del término legal, por lo que el demandado sólo podía pedir la reproducción de las declaraciones ya realizadas. El juez dispuso no hacer lugar al incidente planteado por aquél al impugnar a los testigos, fundamentándose en la autoridad del Código, que en sus artículos 243 al 249 se expide acerca de éstos ${ }^{50}$.

En ese intervalo Ruiz presentó dos testigos. Uno de ellos, Pedro Noally, de 36 años, francés, carpintero, tonelero - una actividad relacionada con la creciente industria vitivinícola en la provincia-, domiciliado en la Colonia [Francesa], expuso sobre el precio de la ventana y marco de puerta realizados por Ruiz a la Sra. Fuentes, que a su entender era de 38 pesos. A continuación, declaró Dn. Pío Ara, de 47 años, casado, español y reconocido comerciante domiciliado en esa localidad de 25 de mayo. Éste, luego de las formalidades de rigor, respondió a la pregunta de si le constaba que en la cuenta presentada por Ruiz había trabajos realizados por él, cuáles eran y cuánto podrían valer: que la yunta de bueyes para arar, y el carro y peón para traslado de ladrillos, les fueron facilitados por el testigo, habiéndole cobrado por lo primero 2,5 pesos y por lo segundo, 5 pesos. En cuanto a la solera, que este trabajo lo había hecho Ruiz cuando vivía en casa

${ }^{49}$ Artículo 556: "El término de prueba no podrá pasar de diez días en las causas ante los Decuriones, $y$ de veinte en las que pendan ante los Jueces de Paz, aumentando, en uno u otro caso, un día cada veinticinco kilómetros, cuando la prueba hubiere de producirse fuera de la respectiva jurisdicción": Código de Procedimientos en materia Civil, cit. (n. 24).

${ }^{50}$ En sus artículos 243 al 249 el Código prescribe acerca del modo en que se debía proceder para la tacha de testigos. 
del declarante. En la misma acta se asentó que el demandado no negaba la deuda por la manutención de un peón, ante lo cual la actora solicitó al juez que le pusiera precio, y dijo que como ella reconocía un monto a favor del demandado, solicitaba que le pagase el saldo. También manifestó no reconocer la cuenta por él presentada, puesto que contenía partidas que no le correspondían a ella, quien no era dueña del inmueble ni había contratado trabajos a realizarse en el mismo, y que los testigos no dijeron exactamente qué trabajos había realizado Ruiz en la casa. El 7 de diciembre comparecieron los litigantes y declararon no haberse puesto de acuerdo, por lo que se les notificó la sentencia expedida el 1 de diciembre a favor de Da. Adela Fuentes.

No obstante, como hasta el 21 de diciembre no se había hecho el pago, ya cumplidos los quince días hábiles la mujer volvió a comparecer para solicitar se expidiese el mandamiento de estilo para que el pago se hiciese efectivo. No obstante, tuvo que esperar más de un año -hasta el 11 de marzo de 1907- para que se realizara el embargo de un coche a Ruiz, a solicitud de ella. Ante esto, el demandado declaró que ese bien pertenecía a otro hombre que lo había dejado en su taller, y que por tal motivo pedía el levantamiento del embargo y la devolución del coche. Ese mismo día Fuentes solicitó el remate del carro porque se sabía que era del deudor, a lo que el juez accedió en fecha 15 de marzo de 1907. El 29 de marzo, es decir más de diez días después de que se dispusiese el remate, se presentó ante el juzgado Dn. Eusebio Ruiz para saldar la cuenta, incluyendo los gastos originados por el juicio. Solicitó también, y se le concedió, que el expediente fuera archivado y levantado el embargo, y el coche le fue devuelto.

Como puede observarse, el juicio concluyó luego de más de un año desde su iniciación. La dilación no se produjo en los pasos seguidos hasta la sentencia -40 días-, sino en el cumplimiento de la misma, es decir en el embargo y ejecución. Puede suponerse que la demora fue posible porque el demandado no tenía bienes con los cuales responder, o por su habilidad para ocultarlos, o bien porque pudo hacer valer sus vinculaciones con hombres influyentes de la sociedad local, como el comerciante español Pío Ara. Pero el tesón de la demandante finalmente logró que el fallo se cumpliera. Se advierte, además, como en otros expedientes, la mención al Código Procesal como fundamento de las determinaciones tomadas por el juez, algo a lo que también podían recurrir las partes en defensa de sus posiciones, como lo hizo en este caso la actora.

Como era de esperar en una sociedad con una alta proporción de inmigrantes, aparecen litigando miembros de colectividades extranjeras, no sólo como demandados, como en el caso de Di Fiori, en el que aunque no se expresa su nacionalidad, es fácil suponerla. También intervienen en calidad de actores y testigos, y asimismo como apoderados, como en el expediente que citamos a continuación.

Este último expediente que hemos elegido para analizar no se inicia por incumplimiento de contrato, sino por daños ocurridos en una propiedad por negligencia de un inspector de hijuela. La provincia de Mendoza presenta una geografía semidértica, cuya producción depende del agua derivada de los ríos por canales e hijuelas. El inspector era una autoridad que debía ocuparse del buen estado del surco a su cargo, no sólo para que el agua llegase en la cantidad necesaria y 
equitativa a las distintas fincas, sino también con el fin de que no se produjeran los daños a las propiedades y vías de comunicación debidos a su mal mantenimiento, lo que por lo caudaloso de los ríos del sur mendocino ocasionaba perjudiciales derrames e inundaciones. El juicio, que se inició en 1916 y duró hasta 1918, dio lugar a un grueso expediente, que inició Carlos Wauters, “argentino, mayor de edad, casado, ingeniero civil, domiciliado en Las Paredes de esta jurisdicción y fijando domicilio legal en la puerta del juzgado". Éste entabló demanda por la cantidad de 360 pesos, contra Domingo Piestralini en su carácter de "Inspector de la Hijuela $N^{\circ} 5$ del Canal Las Paredes, quien debía conservarla y mantenerla en buen estado sin conseguirlo en forma alguna" en el tramo que corría frente a su propiedad, produciéndose el deterioro de alambrados, pérdida de cercos y plantaciones y socavaciones bajo la casa del encargado de la finca.

Citadas las partes al tercer día hábil posterior a la notificación, y no consiguiéndose ningún arreglo, ambos de común acuerdo pidieron se nombrase un árbitro o mediador, para que viese en qué consistían los daños y estimase su valor. La tarea fue encomendada al vecino Francisco Cía, quien debió manifestar su aceptación en forma. Trasladado éste al lugar del hecho, constató los perjuicios ocurridos en los $2 \mathrm{~km}$ de frente de la finca de Wauters, debidos a la falta de conservación de la hijuela, y avaluó los mismos en 180 pesos, es decir en la mitad de lo que solicitó el demandante. Se aclaró que la suma correspondía al $50 \%$ de la destrucción ocasionada por los derrames totales de la hijuela, ya que del total de propiedades regadas por la hijuela ése era el porcentaje correspondiente al demandante. La providencia del árbitro fue expedida en una cédula que el auxiliar de justicia fijó en la puerta del juzgado, donde también el demandado había establecido su domicilio legal. Vencido el término para que el inspector cumpliese, el juez dictó sentencia condenándolo a pagar 180 pesos por daños y perjuicios. Como el pago no se produjo, Wauters solicitó se librase mandamiento de embargo y ejecución, y acompañaba una suma de gastos inherentes al juicio, correspondientes a la pericia realizada por Cía, dos notificaciones del auxiliar de justicia (una de las veces fue el propio Cía), y sellos. Para terminar el juicio, se hizo cargo de representar a Wauters el señor Enrique Geiger, extranjero, mayor de edad, quien fijando domicilio en los estrados del juzgado presentó poder otorgado por aquél en legal forma ante el notario de San Rafael.

Este juicio, a diferencia de la mayoría, no tuvo una rápida resolución, y no sabemos si ello se debió a intereses políticos en pugna, algo posible porque las partes pertenecían a un sector social más alto: al menos el demandante era miembro prestigioso de la élite ${ }^{51}$. El litigio se inició en torno a una de las cuestiones centrales para la vida y la producción de la provincia: el mantenimiento de acequias y los intereses que podían verse conculcados por la negligencia en la administración del

${ }^{51}$ En 1906, el Ing. Wauters realizó un estudio técnico sobre las aguas del Atuel; también se deben a él proyectos sobre el uso del agua, y planos para otras partes del país. En 1910 compró a Alfredo Israel 11.000 has. donde posteriormente surgirá el distrito de Real del Padre, perteneciente al departamento de San Rafael. CANTARELLI, Andrea, El frente pionero en San Rafael y la conexión ferroviaria de 1903, en Actas XX Jornadas de Historia Económica (Mar del Plata, Facultad de Humanidades, UNMdP, 2006). 
agua. En él se muestra, por otra parte, la actividad que desarrollaron un conjunto de auxiliares de justicia que se alternaban en el desempeño de distintos roles. Es de destacar, entonces, que además de la amplia mayoría de juicios por compromisos verbales, los hubo relativos a otras cuestiones, como el que acabamos de mencionar. Varios lo fueron también por la falta de pago de tasas a la municipalidad, y algunos por deudas arrendamiento de terrenos de propiedad de un banco, en los que lo común fue que se presentara a litigar un apoderado de la institución. Cuando se trató de tasas municipales el deudor fue invariablemente condenado a pagar y en los otros casos también hubo sentencia en ese sentido si el moroso no arreglaba antes con la contraparte, pudiéndose llegar al embargo y remate de bienes.

\section{CONSIDERACiOnes Finales}

La justicia de paz fue organizada formalmente por las sucesivas constituciones, las correspondientes leyes orgánicas, y los códigos de fin de siglo XIX, de acuerdo con el positivismo jurídico vigente entonces. Sin embargo, hemos podido observar que la ley no le sustrajo las particularidades que hacían de ella una justicia sui generis, puesto que el discernimiento del juez siguió ocupando un lugar relevante en la substanciación de los juicios, y además conservó sus caracteres de conciliatoria, paternal y, en general, rápida, sobre todo en aquellos juicios que por su cuantía podrían considerarse de cuestiones casi domésticas.

Los juicios en materia civil y comercial analizados, muestran, primeramente, el lugar destacado que ocupaban los contratos verbales, como un modo corriente de regular las transacciones y contraprestaciones entre los vecinos. Mediante estos acuerdos, que obviamente no quedaban protocolizados ante escribanos ni se asentaban por lo general en papel firmado privadamente por las partes, se realizaban arriendos de propiedades, muchas veces a cambio de la mejora de las mismas; compraventa de animales, contratos laborales y acuerdos de fiado y de intercambio de mercaderías y o de prestaciones de servicios, vale decir todo lo relativo a la pequeña economía vecinal. Tales transacciones tenían alcances jurídicos, puesto que los vecinos podían presentarse por sí o a través de un apoderado -aunque esto no era lo corriente- para reclamar su cumplimiento. Ello demuestra el alto valor de la palabra en esa sociedad local, en la que hasta una promesa verbal de venta podía generar derechos y obligaciones. Una cuenta reconocida por testigos o firmada por la parte contraria podía servir de prueba en el reclamo de los derechos conculcados, acción que era realizada por lo general por el propio damnificado.

Es de destacar que, con alguna elasticidad, lo corriente fue que se substanciaran los juicios con la rapidez pretendida por el Código de Procedimientos para la justicia de paz -como surge de las fechas consignadas en los expedientes-, de allí que pueda decirse que esta justicia lega, constituyó un rápido y eficaz medio de solución de los conflictos cotidianos. Si bien todos podían presentarse a litigar ante este estrado -nacional o extranjero, hombre o mujer, y de cualquier condición social- eran comúnmente los sectores medios de la sociedad local los que se presentaron a hacerlo en cuestiones de materia civil y comercial, es decir los que tenían algo que perder. También personas de un mayor nivel social recurrieron 
ante esta magistratura, como hemos podido comprobar, cuando sus intereses conculcados lo eran dentro de los montos correspondientes a esa justicia.

No hemos hallado en los expedientes del juzgado de paz en materia civil o y comercial indicios de prácticas arbitrarias contra las cuales pudieran quejarse los actores, algo que obviamente podía no ser explícito en actas redactadas bajo la vigilancia del juez. Pero tampoco hemos encontrado denuncias en la prensa de la época, salvo en materia electoral por prácticas fraudulentas en la inscripción en los padrones realizada por los jueces, y en lo concerniente a la administración de justicia, por algún caso de lentitud en resolver los casos. Consta, sí, un pedido de renuncia por parte de la municipalidad por dejadez en el cumplimiento de su tarea en el juzgado. Es decir, nada que pudiera parecerse a las críticas realizadas años atrás a los subdelegados, magistrados rurales que ejercieron hasta 1872 la justicia de $1^{\circ}$ instancia, la policía de seguridad, la presidencia de la municipalidad $-y$ ante cuyo poder las municipalidades rurales por lo general se doblegaron. En esta figura se hallaba más concentrado el poder local, pero los jueces de paz de principios del siglo XX, parecen haber perdido prácticamente su papel político, salvo en lo relativo a lo mencionado sobre la inscripción en los padrones. No tenían facultades policiales como los del siglo XIX, por lo que cumplían, dentro de la división de funciones, la judicial casi con exclusividad. Digamos que a principios del siglo XX existía en el orden local una constelación de autoridades: el jefe político (policía de seguridad y agente del gobierno), la municipalidad, el juez de paz, en lo que podría considerarse una especie de equilibrio de poderes, característica que al menos puede señalarse para el progresista departamento de San Rafael. Probablemente las prácticas participativas de los inmigrantes tuvieron incidencia en ello.

Si nos preguntamos por el grado de estatalización de esa sociedad de reciente colonización del Sur mendocino en lo referente a la administración de justicia, debemos reconocer que no es algo que pueda inferirse con exactitud de las fuentes con que contamos, en parte por lo escaso de su número. Sin embargo, ellas nos permiten una aproximación al funcionamiento de la justicia de paz, que se muestra bastante aceitado. El apego a las leyes orgánicas y a los códigos en los procedimientos -no obstante el expreso mandato al juez de obrar sólo según su conciencia si el caso lo requería-y, al mismo tiempo, la capacidad mostrada por la institución para arbitrar en el conflicto vecinal con cierta eficacia, es un indicio de la consolidación institucional en esa sociedad del Sur mendocino, sin que perdiera su carácter de mediadora en la sociedad civil y entre ésta y el Estado.

[Recibido el 1 y aprobado el 31 de julio de 2010].

\section{BiBLIOGRAFÍA}

ABÁsolo, Ezequiel, Las notas de Dalmacio Vélez Sársfield como expresiones del "ius commune" en la apoteosis de la codificación, o de cómo un código decimonónico pudo no ser la mejor manifestación de la "Cultura del Código", en Revista de Estudios Histórico Jurídicos, 26 (Valparaíso, 2004). 
ACCATINO SCAGLIOTti, Daniela, Elsaber dogmático en nuestra cultura jurídica, en Revista de Derecho, 8 (Valdivia, Universidad Austral de Chile, diciembre 1997).

BARRIERA, Darío G., Justicias, jueces y culturas jurídicas en el siglo XIX rioplatense. Nuevo Mundo Mundos Nuevos (Debates, 2010, puesto en línea el 23 marzo 2010; URL : http://nuevomundo.revues.org/59252).

BERNARD, Tomás, Régimen municipal argentino. Origen institucional y su evolución hasta la época actual (Buenos Aires, Depalma, 1975).

Cantarelli, Andrea, Contratistas de plantación: agentes geográficos en los comienzos de la viticultura moderna en San Rafael, Mendoza, 1880-1914, en Anuario del Centro de Estudios Históricos "Prof. Carlos S. A. Segretti", 9 (Córdoba, Centro de Estudios Históricos, en prensa).

CANTARELli, Andrea, El frente pionero en San Rafael y la conexión ferroviaria de 1903, en Actas XX Jornadas de Historia Económica (Mar del Plata, Facultad de Humanidades, UNMdP, 2006).

Código de Procedimientos en materia Civil y Comercial de la Provincia de Mendoza, 1895, en Compendio de Leyes usuales de la Provincia. Con todas la modificaciones introducidas hasta el 31 de diciembre de 1924 (Buenos Aires: G. Kraft Impresora, 1925), XVIII.

Constituciones de la Provincia de Mendoza hasta 1915 (Edición Oficial, Mendoza, 1915).

EGÜES, Carlos, Historia constitucional de Mendoza. Los procesos de reforma (Mendoza, Ediunc, 2008).

Hespanha, Antonio, Cultura juridica europea. Sintesis de un milenio (Madrid, Tecnos, 2002).

Palacio, Juan Manuel, Hurgando en las bambalinas de "la paz del trigo": Algunos problemas teórico-metodológicos que plantea la historia judicial”, en Quinto Sol, 9-10 (La Pampa, 2005-2006).

Recopilación de Leyes desde el $1^{\circ}$ de enero de 1896 al 31 de diciembre de 1924 correspondientes al Ministerio de Gobierno (Mendoza, 1925), III.

Richard-Jorba, Rodolfo, Poder, espacio y economía en Mendoza, 1850-1900 (Mendoza, Facultad de Filosofía y Letras, UNCuyo, 1998).

SAnjurjo, Inés Elena, Justicia de paz y cultura jurídica en el largo siglo XIX en Mendoza (Argentina). El caso del departamento de San Rafael en el sur provincial, en Nuevos Mundos Mundos Nuevos, Debates, 2010, en línea desde el 23 marzo 2010. URL : http://nuevomundo.revues.org/59257).

Sanjurjo, Inés Elena, La justicia de paz en Mendoza. Leyes de 1872, 1876 y 1880, en Confluencia, 2 (Mendoza, primavera 2003, Facultad de Ciencias Políticas y Sociales, UNCuyo).

SAnjurjo de Driollet, Inés, Frontera indigena y colonización agricola, en RichardJORBA, Rodolfo y otros La región vitivinícola argentina. Transformaciones del territorio, la economía y la sociedad, 1870-1914 (Buenos Aires, Universidad Nacional de Quilmes Editorial, 2006).

SAnjurjo de Driollet, Inés, Muy ilustre Cabildo Justicia y Regimiento. Estudio institucional del cabildo de Mendoza en el siglo XVIII (Mendoza, Facultad de Filosofía y Letras, UNCuyo, 2005).

SANJURJo DE DrIOlLET, Inés, La organización politico-administrativa de la campaña mendocina en el tránsito del antiguo régimen al orden liberal (Buenos Aires, Instituto de Investigaciones de Historia del Derecho, 2004). 
Tau AnzoÁtegui, Víctor, La codificación en la Argentina (Buenos Aires, Instituto de Historia del Derecho Ricardo Levene, 1977).

Tiscornia, Sofía, Entre el imperio del "Estado de Policía" y los límites del Derecho, en Nueva Sociedad, 191 (Buenos Aires, mayo-junio de 2004). 